\title{
KAT5 (Tip60) is a potential therapeutic target in malignant pleural mesothelioma
}

\author{
SIAN CREGAN ${ }^{1-3}$, LAURAN McDONAGH $^{4}$, YUN GAO $^{1,5}$, MARTIN P. BARR $^{1,4}$, \\ KENNETH J. O'BYRNE ${ }^{1,6}$, STEPHEN P. FINN ${ }^{7}$, SINEAD CUFFE $^{8}$ and STEVEN G. GRAY ${ }^{1,4}$ \\ ${ }^{1}$ Thoracic Oncology Research Group, Institute of Molecular Medicine, St. James's Hospital, Dublin; \\ ${ }^{2}$ Department of Surgery, ${ }^{3}$ MSc in Translational Oncology Program, and ${ }^{4}$ Department of Clinical Medicine, \\ Trinity College Dublin, Dublin, Ireland; ${ }^{5}$ Department of Oncology, Aerospace Central Clinical Medical \\ College of Peking University, Beijing, P.R. China; ${ }^{6}$ Cancer and Ageing Research Program, Queensland \\ University of Technology, Brisbane, Australia; ${ }^{7}$ Department of Histopathology and Morbid Anatomy, \\ Trinity College Dublin, Dublin; ${ }^{8}$ HOPE Directorate, St. James's Hospital, Dublin, Ireland
}

Received November 3, 2015; Accepted December 16, 2015

DOI: 10.3892/ijo.2016.3335

\begin{abstract}
Malignant pleural mesothelioma (MPM) is a rare aggressive cancer of the pleura. Asbestos exposure (through inhalation) is the most well established risk factor for mesothelioma. The current standard of care for patients suffering from MPM is a combination of cisplatin and pemetrexed (or alternatively cisplatin and raltitrexed). Most patients, however, die within 24 months of diagnosis. New therapies are therefore urgently required for this disease. Lysine acetyltransferases (KATs) including KAT5 have been linked with the development of cisplatin resistance. This gene may therefore be altered in MPM and could represent a novel candidate target for intervention. Using RT-PCR screening the expression of all known KAT5 variants was found to be markedly increased in malignant tumors compared to benign pleura. When separated according to histological subtype, KAT5 was significantly overexpressed in both the sarcomatoid and biphasic subgroups for all transcript variants. A panel of MPM cell lines including the normal pleural cells LP9 and Met5A was screened for expression of KAT5 variants. Treatment of cells with a small molecule inhibitor of KAT5 (MG-149) caused significant inhibition of cellular proliferation $(\mathrm{P}<0.0001)$, induction of apoptosis and was accompanied by significant induction of pro-inflammatory cytokines/chemokines.
\end{abstract}

\section{Introduction}

Malignant pleural mesothelioma (MPM) is an aggressive inflammatory cancer, predominantly arising from prior expo-

Correspondence to: Dr Steven G. Gray, Thoracic Oncology Research Group, Room 1.06, Trinity Centre for Health Sciences, Institute of Molecular Medicine, St. James's Hospital, Dublin 8, Ireland

E-mail: sgray@stjames.ie

Key words: mesothelioma, lysine acetyltransferase, epigenetics, MG 149, inflammation sure to asbestos (1). An extended lag period between exposure and disease onset coupled with the non-descript nature of the symptoms associated with this disease means that the vast majority of patients when diagnosed present at an advanced stage. Overall survival for MPM is poor with most patients dying within one year of diagnosis $(2,3)$. A conservative estimate has suggested that globally $\sim 43,000$ people die from this disease annually, but the actual number is probably much greater (4,5). Although there has been some recent advances in this disease, current standard of care is a combination of pemetrexed and cisplatin chemotherapy (6), which is non-curative and results in a response rate of $\sim 40 \%$ (7). Consequently, there is an urgent need to identify novel therapeutic avenues in this disease to improve patient outcomes.

Epigenetics is often described as 'chromatin-based events that regulate DNA-templated processes' (8). Furthermore, it is also now well established that aberrant epigenetics are a common feature in cancer, including mesothelioma (9).

Epigenetic regulation of chromatin is often described as a code (10) involving regulatory proteins that act as 'readers', 'writers' or 'erasers' of this code. The majority of these proteins utilize various post-translational modifications such as histone acetylation on core histones to elicit responses (11). The enzymes which write/erase histone acetylation are called lysine acetyltransferases (KATs) and histone deacetylases (HDACs), respectively (12). Since their discovery, significant effort has been expended by the pharmaceutical sector to develop agents that target these proteins. One such compound, vorinostat, is a histone deacetylase inhibitor FDA approved for the treatment of cutaneous T-cell lymphoma (13), was tested in a phase III clinical trial as a second or third-line treatment in MPM, but unfortunately did not improve overall survival and cannot be recommended as a therapy for patients with MPM (14).

Lysine acetyltransferases are also emerging as candidate therapeutic targets in cancer with the recent development of several inhibitors targeting these proteins $(15,16)$. There are, however, a significant number of KATs and the KAT 
superfamily itself can be separated into several subfamilies (17). One of these is the MYST family comprising KAT5-KAT8 (18). MYST KATs have diverse functions affecting the majority of cellular processes, ranging from gene regulation, cell cycle, stem cell homeostasis and development and critically DNA damage repair (18). A member of the MYST family, KAT5 (also known as Tip60) is the catalytic subunit of the $\mathrm{NuA} 4$ histone acetyltransferase complex which is involved in transcriptional activation of select genes. This complex may be required for the activation of transcriptional programs associated with oncogene and proto-oncogene mediated growth induction, tumor suppressor mediated growth arrest and replicative senescence, apoptosis and DNA repair $(19,20)$. Critically, KAT5 has now also been linked to: i) activation of excision repair cross-complementation group 1 (ERCC1) a critical DNA damage repair protein in response to exposure to cisplatin (21); and ii) with the development of cisplatin resistance (22). As such, given that the standard first-line therapy for MPM is cisplatin based (6), we examined whether the expression of KAT5 is altered in MPM and if this protein could represent a novel candidate target for intervention in this disease. Our results show that KAT5 is significantly elevated in MPM, and targeting this protein with small molecule inhibitors results in insignificant anti-proliferative and apoptotic responses in MPM cell lines, further underlining the therapeutic potential of targeting this protein in mesothelioma.

\section{Materials and methods}

Primary tumor samples. Surgical specimens were obtained as discarded tumor samples from patients who had undergone extended pleuro-pneumonectomy at Glenfield Hospital (Leicester, UK). Benign specimens were acquired from patients never diagnosed with MPM. Informed consent was obtained from each patient, and the study was conducted after formal approval from the relevant Hospital Ethics Committee. Samples consisted of the following: 5 benign lesions and 17 MPM samples (epithelioid, $n=7$; biphasic, $n=6$; and sarcomatoid, $\mathrm{n}=4$ ).

Cell culture. All MPM cell lines were maintained in a humidified atmosphere containing $5 \% \mathrm{CO}_{2}$ in appropriate media supplemented with $10 \%$ fetal bovine serum (FBS) and penicillin streptomycin $(500 \mathrm{U} / \mathrm{ml})$. Cell culture reagents were purchased from Lonza (Walkersville, MD, USA). Twenty-four MPM cell lines were used in the study: LP9, Met5A, NCI-H2596, MMP, MMB, NCI-H2052, NCI-H28, Ju77, One58, RS-5, DM-3, ACC-MESO-1, ACC-MESO-4, Y-MESO-8D, Y-MESO-9, Y-MESO-12, Y-MESO-14, M14K, M24K, M25K, M28K, M33K, M38K and LO68.

LP9, MMP and MMB were a generous gift from Dr Warren Thomas (Royal College of Surgeons in Ireland, Dublin, Ireland). ACC-MESO-1, ACC-MESO-4, Y-MESO-8D, Y-MESO-9, Y-MESO-12 and Y-MESO-14 were generously provided by Yoshitaka Sekido (Aichi Cancer Center Research Institute, Nagoya, Japan). NCI-H2052, One58 and JU77 cells were provided by Duncan Stewart (University of Leicester, Leicester, UK). The NCI-H2596 and REN cell lines were kindly provided by Dean Fennell (Queen's University, Belfast,
Northern Ireland). M14K, M24K, M25K, M28K, M33K and M38K were generously provided by Dr Hannu Norppa (Finnish Institute of Occupational Health, Helsinki, Finland). NCI-H28, and the immortalized non-tumorigenic mesothelial cell line, Met-5A were purchased from the ATCC (LGC Promochem, Teddington, UK). RS-5 and DM-3 were purchased from the DSMZ (Leibniz Institute DSMZ-German Collection of Microorganisms and Cell Cultures, Braunschweig, Germany).

Reagents. MG 149 (23) was purchased from Axon Medchem BV (Groningen, The Netherlands), and dissolved in dimethyl sulfoxide (DMSO). Cells were serum starved (0.5\% FBS) for $24 \mathrm{~h}$ prior to the addition of drugs.

Proliferation assay. Cell proliferation was measured using a Cell Proliferation BrdU ELISA (Roche Diagnostics Ltd., West Sussex, UK), according to manufacturer's instructions. Briefly, cells (REN or H26) were seeded at $3 \times 10^{3} /$ well in a 96 -well plate. Following overnight incubation, cells were treated for $24 \mathrm{~h}$ with MG 149 at $1,5,10,15,20$ and $25 \mu \mathrm{M}$. Absorbance was measured on a plate reader at $450 \mathrm{~nm}$ with a reference wavelength set to $690 \mathrm{~nm}$. Untreated wells were used for normalization purposes and set to $100 \%$.

Cellular apoptosis (FACS). NCI-H226 cells were seeded in 6 -well plates at a density of $1 \times 10^{5}$ cells/well and were allowed to adhere overnight. Subsequently the complete media was removed and the cells washed with $100 \mathrm{ml}$ PBS. Serum depleted media (0.5\% FBS) was added and the cells incubated for a further $24 \mathrm{~h}$, then treated with appropriate concentrations of drug, diluted in cell culture media, for a further $48 \mathrm{~h}$. Where appropriate, control cells were treated with either vehicle or left untreated with media only. Following treatment, culture media was removed, transferred to labeled FACS tubes and placed on ice. Adhered cells were then trypsinised and transferred to corresponding FACS tubes. Cells were pelleted by centrifugation at 1,300 rpm for $3 \mathrm{~min}$ and the supernatant removed. The cells were washed in $1 \mathrm{ml}$ of $1 \mathrm{X}$ binding buffer (BB) diluted in ice cold PBS, pelleted by centrifugation and resuspended in $100 \mu \mathrm{l} \mathrm{BB}$. Annexin V $(2 \mu \mathrm{l})$ (IQ Products, Groningen, The Netherlands) was added to each tube, with the exception of the negative control and media only samples, and cells were incubated at $4^{\circ} \mathrm{C}$ for $20 \mathrm{~min}$, protected from light. Cells were again washed in $1 \mathrm{ml} 1 \mathrm{X}$ binding buffer and supernatant removed. Immediately before analysis by flow cytometry, cells were resuspended in $400 \mu \mathrm{l} \mathrm{BB}$ containing $0.5 \mu \mathrm{g} / \mathrm{ml}$ PI (Invitrogen, Paisley, UK), except the negative control and FMO (fluorescence minus one) control for PI for which $\mathrm{BB}$ alone was used.

Caspase-3/7 activation. Activation of caspase-3/7 was measured using a FluoroFire Caspase-3/7 fluorescent assay kit according to the manufacturer's instructions (Molecutools, Dublin, Ireland). NCI-H226 cells were seeded in 96-well plates at a density of $4 \times 10^{3}$ cells/well and were allowed to adhere overnight. Subsequently the complete media was removed and the cells washed with $100 \mathrm{ml}$ PBS. Serum depleted media $(0.5 \% \mathrm{FBS})$ was added and the cells incubated for a further $24 \mathrm{~h}$, then treated with appropriate concentrations of drug, diluted in cell culture media, for a further $48 \mathrm{~h}$. 
A

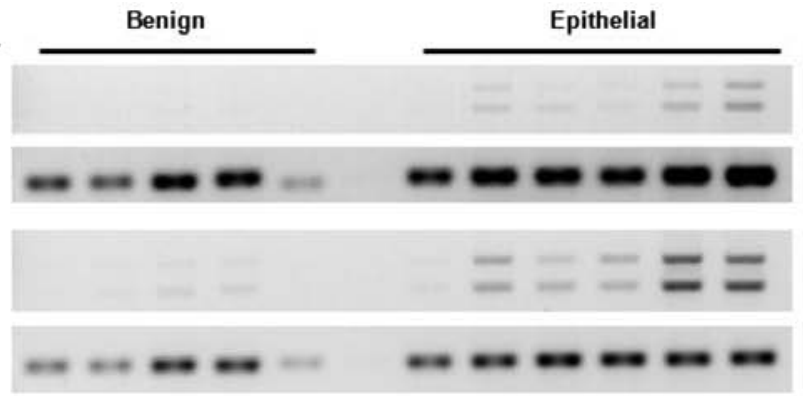

B
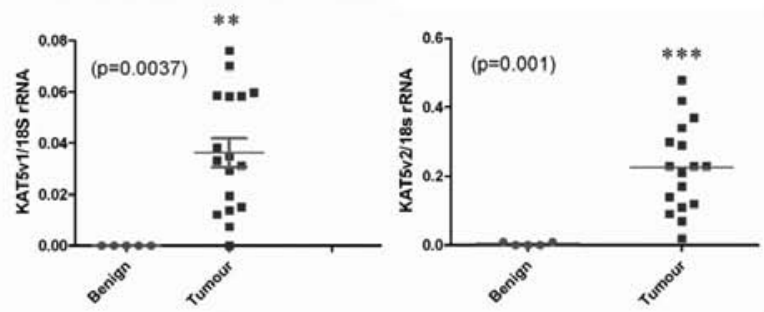

C
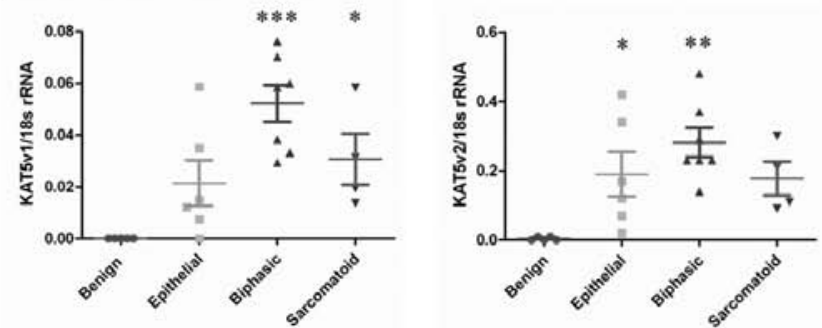
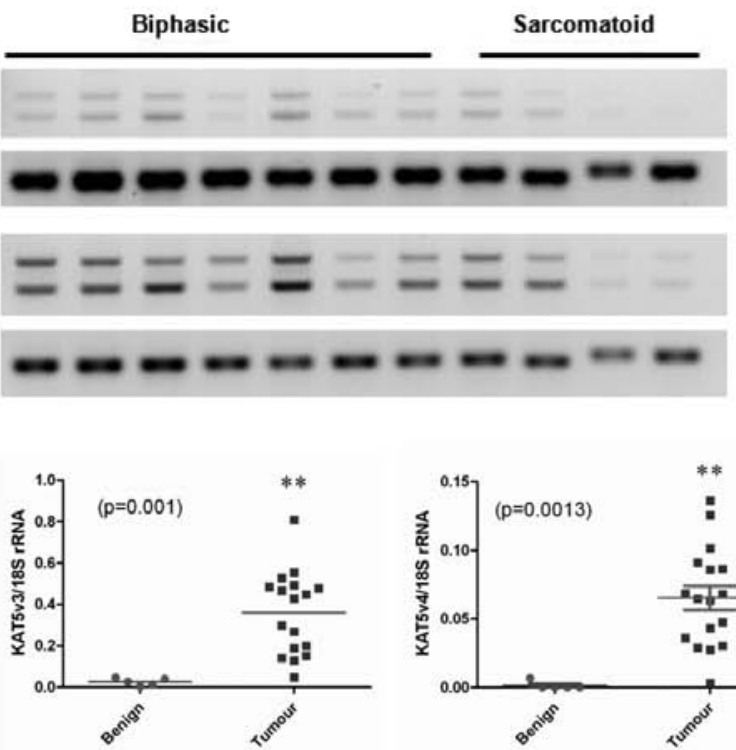

KAT5 v1 KAT5 v4

18s rRNA

KAT5 v2 KAT5 v3 18s rRNA

Figure 1. Expression KAT5 variants in primary malignant pleural mesothelioma vs. benign pleura. (A) RT-PCR showing the expression of the various KAT5 variants and 18s rRNA in a series of benign pleura and malignant tumors. (B) Densitometric analysis of RT-PCR products comparing tumor vs. benign. (C) Stratification according to histological subtype.

RNA isolation and RT-PCR amplification. Total RNA was extracted using TRI reagent ${ }^{\circledR}$ (Molecular Research Center, Cincinnati, OH, USA) according to manufacturer's instructions. Prior to First Strand cDNA Synthesis, $250 \mathrm{ng}$ (primary tumors) or $500 \mathrm{ng}$ (cell lines) total RNA was pre-treated by digestion with Amplification grade DNase I (Sigma-Aldrich, St. Louis, MO, USA) according to the manufacturer's instructions. cDNA was subsequently generated using All-in-One cDNA Synthesis SuperMix (Biotool, Houston, TX, USA) according to the manufacturer's instructions. Cell lines were examined for the expression of KAT5 variants (RefSeq NM_182710.2, NM_006388.3, NM_182709.2 and NM_001206833.1) and 18s rRNA by RT-PCR, using the following primers, or as previously published (24). KAT5v1, 5'-atggcggaggtggtgagtc-3; KAT5v2, 5'-gcggaggtgggggagataat-3'; and KAT5R, 5'-gaaac cacctccaccttccg-3'.

Amplification with KAT5v1 and KAT5R recognizes variants 1 and 4, while amplification with KAT5v2 and KAT5R will amplify variants 2 and 3 .

PCR cycling conditions were $95^{\circ} \mathrm{C}$ for 5 min followed by 35 cycles of $1 \mathrm{~min}$ at $95^{\circ} \mathrm{C}, 1 \mathrm{~min}$ at $58^{\circ} \mathrm{C}, 1 \mathrm{~min}$ at $72^{\circ} \mathrm{C}$, for 35 cycles, with a final extension of $72^{\circ} \mathrm{C}$ for $10 \mathrm{~min}$. A total of $8 \mu \mathrm{l}$ of the experimental RT-PCR product and $2 \mu \mathrm{l}$ of the $18 \mathrm{~s}$ rRNA RT-PCR product was loaded and run on $2 \%$ agarose gel. Following image capture, product quantification was performed using TINA 2.09c (Raytest, Isotopenmeßgeräte
GmbH, Straubenhardt, Germany) densitometry software. The mRNA expression was normalized to the loading control (18s rRNA), and was expressed as a ratio of target mRNA expression: loading control expression.

Analysis of mRNA expression by RT-qPCR. Validation of RT-PCR results was subsequently confirmed using SYBR-Green based quantitative real-time PCR (RT-qPCR). RT-qPCR reactions were carried out for CXCL8 using previously published primers (24). Primers used to analyze CXCL1, and CXCL13 were purchased from Real Time Primers, LLC (Elkins Park, PA, USA).

RT-qPCRs were conducted on an Illumina Eco qPCR using GoTaq ${ }^{\circledR}$ qPCR Master Mix (Promega) using a 2-step qPCR program with the following cycling parameters as recommended by Real Time Primers: An initial polymerase activation of $95^{\circ} \mathrm{C}$ for 2 min followed by 50 cycles of $95^{\circ} \mathrm{C}$ for $10 \mathrm{sec}$ and annealing/amplification at $58^{\circ} \mathrm{C}$ for $45 \mathrm{sec}$. A melting curve analysis was conducted at the end of each PCR using $95^{\circ} \mathrm{C}$ for $15 \mathrm{sec}, 55^{\circ} \mathrm{C}$ for $15 \mathrm{sec}$ and a final $95^{\circ} \mathrm{C}$ for $15 \mathrm{sec}$. Data were analysed using the default in-built $\Delta \Delta \mathrm{Cq}$ analysis settings for relative quantification in Eco software.

Statistical analysis. All data are expressed as mean \pm SEM unless stated otherwise. Statistical analysis was performed with GraphPad Prism v5.01 (GraphPad Software, La Jolla, 


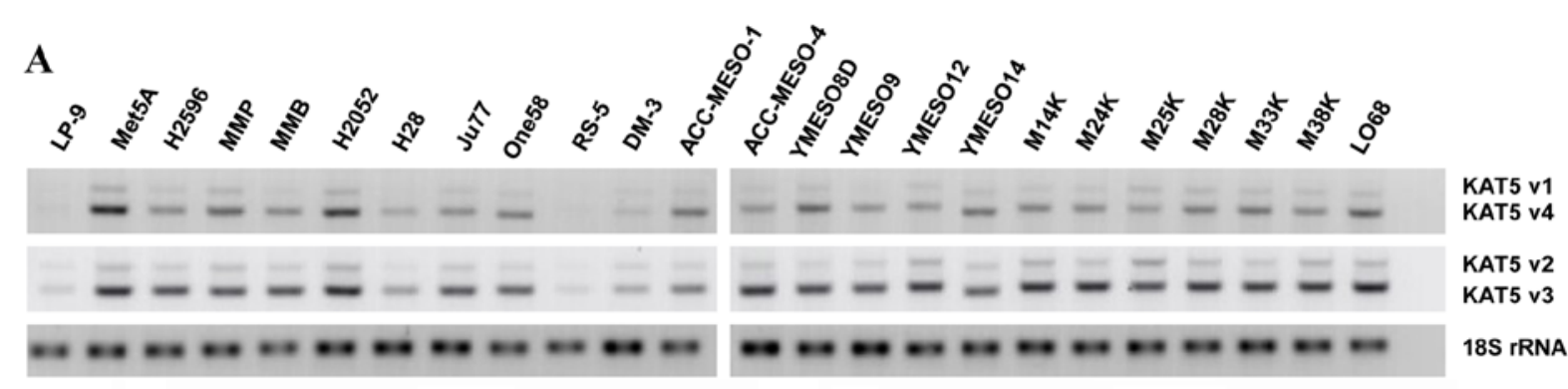

B

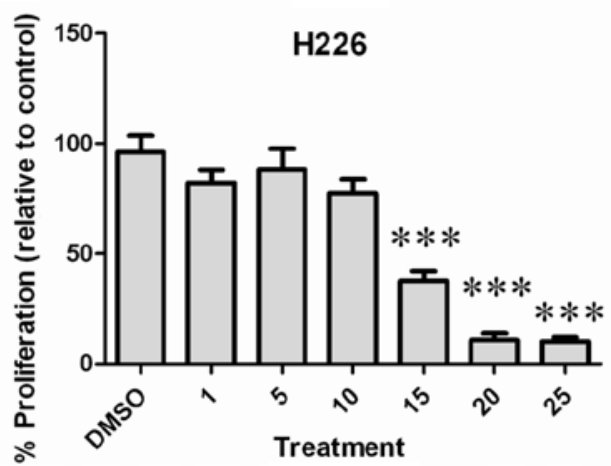

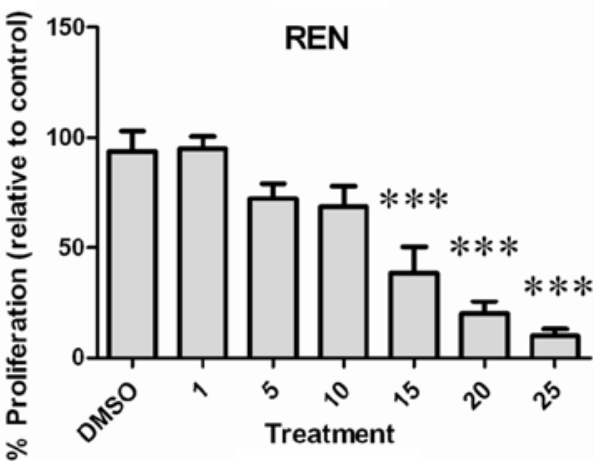

Figure 2. Effects of MG 149 on cellular proliferation in MPM cell lines. (A) RT-PCR showing the expression of the various KAT5A variants in a panel of normal and malignant MPM cell lines. 18s rRNA was included as the loading control. (B) Effects of the MG 149 on cellular proliferation in NCI-H226 or REN cell lines as measured using a BrdU assay. Significance was measured using one-way analysis of variance (ANOVA) with a Dunnett's multiple comparison post-test with all samples compared against the DMSO control.

CA, USA) using either unpaired two-tailed Student's t-test or Mann-Whitney Student's t-test. One-way analysis of variance (ANOVA) was used where groups in the experiment were three or more. Following ANOVA, post-test analyses utilized either the Tukey multiple comparisons test, or the Dunnett's multiple comparison tests.

\section{Results}

Expression of KAT5 in primary mesothelioma specimens. To assess the expression of KAT5 in a panel of fresh-frozen mesothelioma samples with a cohort of benign pleura RT-PCR was performed (Fig. 1A). KAT5 has four known RefSeq variants, and primers were designed to distinguish between all four variants. Densitometric analysis of the RT-PCR products revealed significantly increased expression of all four variants in primary MPM tumor samples compared with normal pleura (Fig. 1B). When stratified according to histological subtype, the most predominant upregulation was observed in the biphasic subtype (Fig. 1C).

Expression of KAT5 in a panel of normal and malignant mesothelial cell lines. Utilizing RT-PCR, the expression of KAT5 was examined in a panel of normal and malignant mesothelioma cell lines (Fig. 2A). All cell lines tested expressed varying levels of KAT5, with higher basal expression observed predominantly in the mesothelioma lines, whereas low basal levels of KAT5 were observed in the normal peritoneal mesothelial cell line LP9 (Fig. 2A).

Inhibition of KAT5 leads to reduced cellular proliferation. A small molecule inhibitor of KAT5 (MG 149) has been developed (23). The effect of this compound was subsequently tested on two cell lines (REN and NCI-H226). At concentrations $>10 \mu \mathrm{M}, \mathrm{MG} 149$ was found to significantly reduce the proliferative rate of both MPM cell types (Fig. 2B).

Inhibition of KAT5 leads to increased cellular apoptosis. As cellular proliferation and viability were affected by treatments with MG 149 we subsequently examined the effects of this compound with respect to cellular apoptosis. Using an Annexin V/FITC based FACs assay, 2.5 or $5 \mu \mathrm{M}$ of MG 149 was found to significantly increase cellular apoptosis at both 24 and $48 \mathrm{~h}$ following treatment (Fig. 3A), and was associated with increased caspase-3/7 activation (Fig. 3B).

MG 149 treatments induce pro-inflammatory cytokine expression. Given the effects of MG 149 on cellular proliferation and apoptosis, and the fact that it targets an epigenetic regulatory protein, we then examined the effects of MG 149 on the expression of members of the CXC $\left(\mathrm{ELR}^{+}\right)$family namely CXCL1-3/GRO $\alpha-\gamma$, CXCL8/IL- 8 and CXCL13. These are proinflammatory chemokines, which we have previously shown to be epigenetically regulated in non-small cell lung cancer (24), and for which some have also been shown to be responsive to asbestos exposure (25). When cells were treated with MG 149 (15 $\mu \mathrm{M}$ for $24 \mathrm{~h})$, RT-PCR analysis showed significant induction/upregulation of four of the chemokines examined (Fig. 4A). Subsequently, using quantitative PCR (qPCR), we confirmed and validated the upregulation of CXCL1 and CXCL8, with a small yet significant downregulation of CXCL13 (Fig. 4B).

\section{Discussion}

In the UK, it is estimated that 91,000 deaths from mesothelioma are predicted to occur from 1968 to 2050 with around 

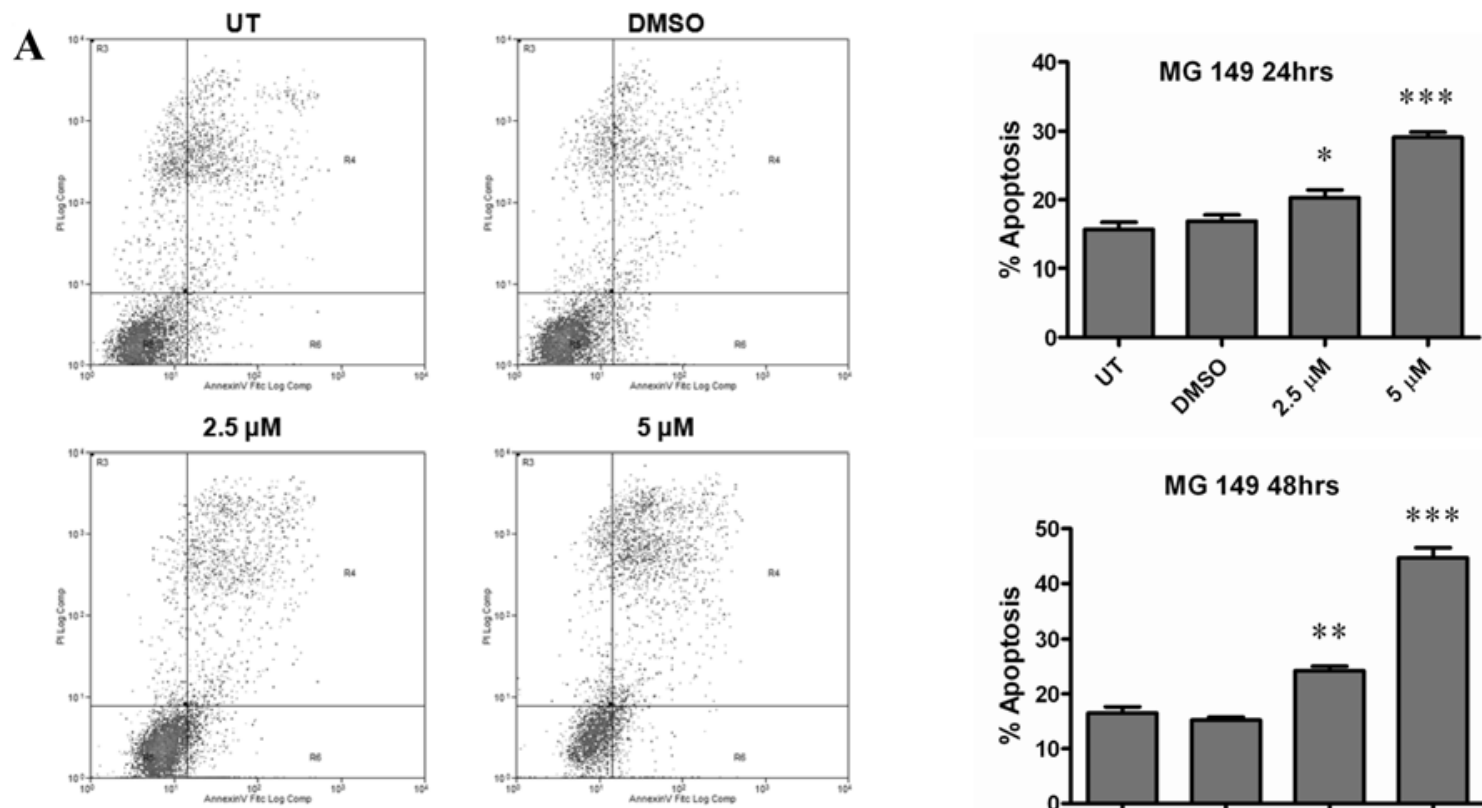

B
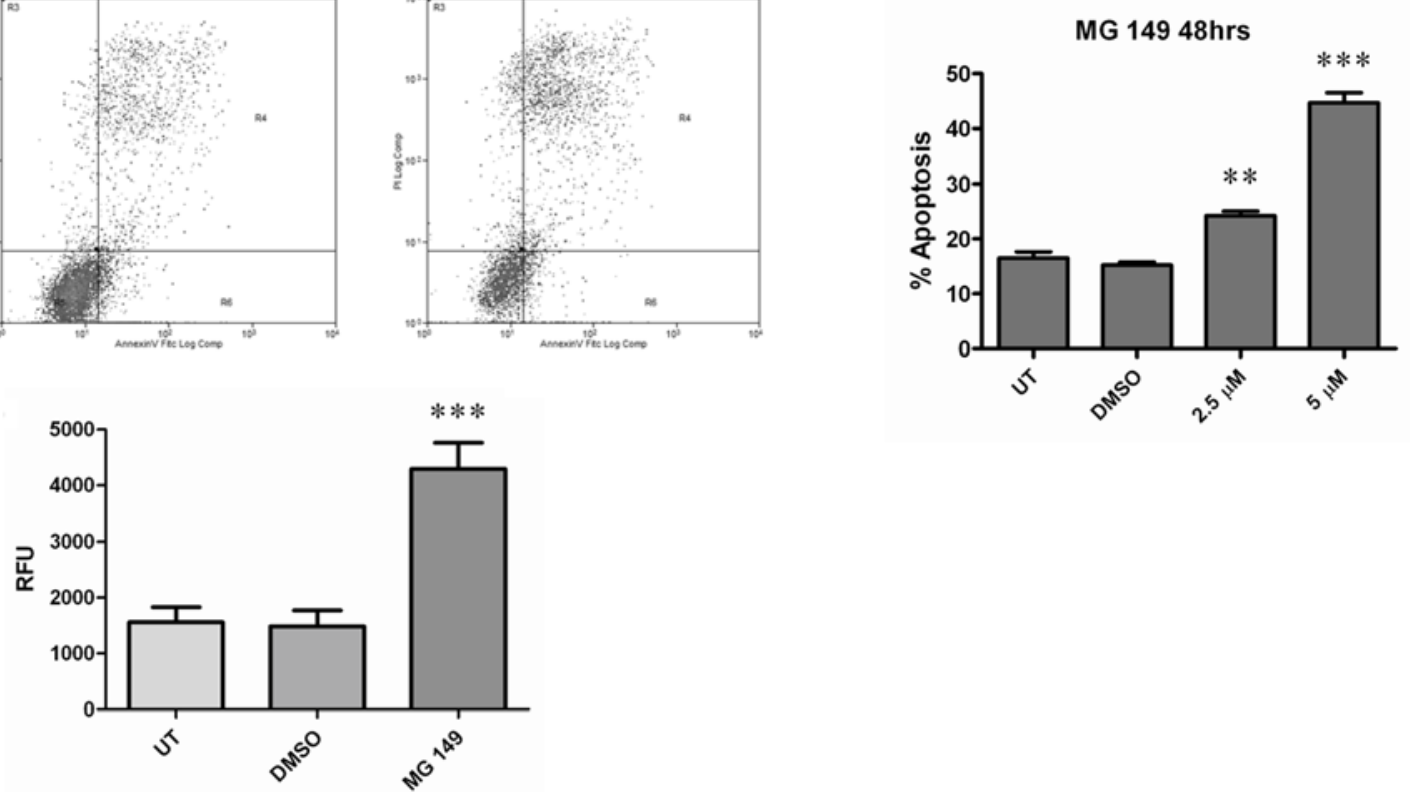

Figure 3. MG 149 induces apoptosis in MPM. (A) Induction of apoptosis by MG 149 in NCI-H226 cells as measured using Annexin V/PI FACs analysis. (B) Induction of caspase-3/7 by MG 149 in NCI-H226 cells. Statistical significance. ${ }^{*} \mathrm{P}<0.05 ;{ }^{* *} \mathrm{P}<0.01 ;{ }^{* * * *} \mathrm{P}<0.001$.

A

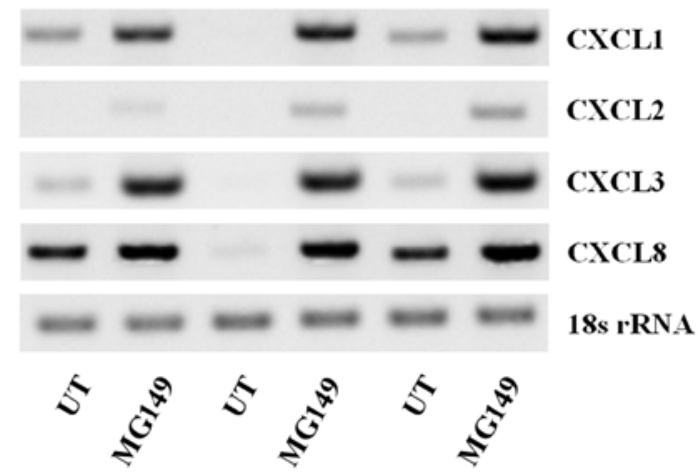

B
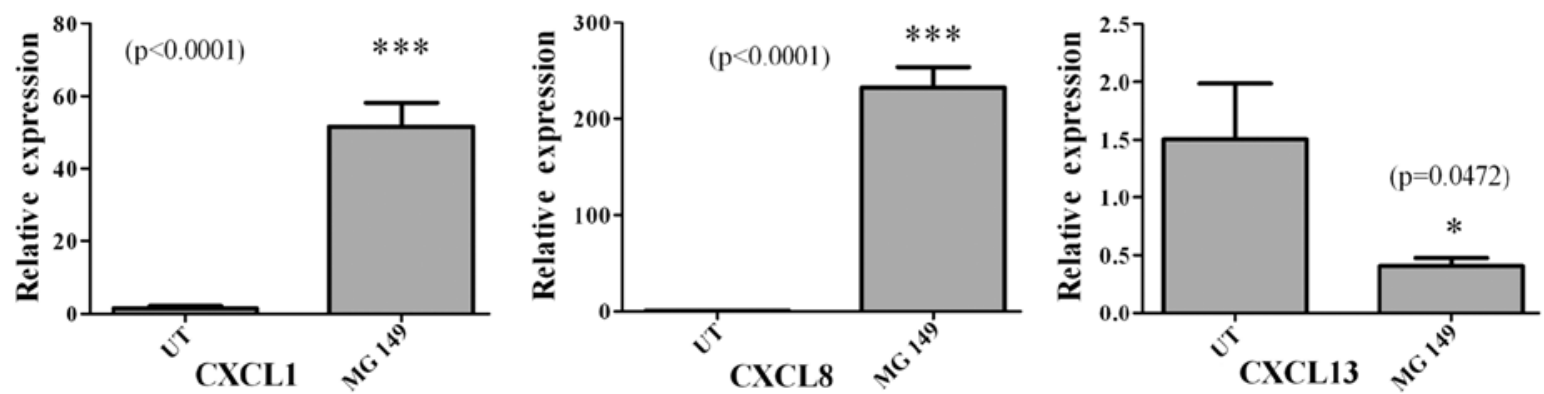

Figure 4. MG 149 alters expression of pro-inflammatory cytokines/chemokines (A) RT-PCR analysis demonstrating the induction of CXCL1, CXCL2, CXCL3 and CXCL8 in cells treated with MG 149. (B) SYBR-Green relative quantification (RT-qPCR) analysis of CXCL1, CXCL8/IL-8 and CXCL13 expression changes in response to treatment with MG 149. Statistical significance was assessed using a paired two-tailed Student's t-test. 
61,000 of these occurring from 2007 onwards (26). The prevailing first-line chemotherapy regimen for mesothelioma remains cisplatin/pemetrexed (or cisplatin/raltitrexed) (6). Critically, only $\sim 40 \%$ of patients respond to this regimen, and we therefore need to identify new agents for the treatment of this cancer.

KAT5 is a member of the lysine acetyltransferases, a large superfamily of epigenetic regulatory proteins which play a number of important cellular roles, and which are emerging as candidate targets for cancer therapy (15). In this regard, KAT5 has been shown to be associated with resistance to cisplatin based therapy in the lung cancer setting $(21,22)$, suggesting that its expression could also be important in mesothelioma cancer. We therefore examined the levels of this lysine acetyltransferase in a panel of primary tumors compared to benign pleura. Our results clearly demonstrated that expression of KAT5 mRNA was significantly elevated in the tumors compared to normal pleura (Fig. 1), and was ubiquitously expressed in a panel of mesothelioma cell lines (Fig. 2). In agreement with our data from primary tumors the expression of KAT5 was less highly expressed in the normal LP9 cell line compared to MPM cancer cell lines (Fig. 2), suggesting that KAT5 may be a potential therapeutic target in mesothelioma.

Several KAT5 specific inhibitors have been developed including MG 149 (23), TH1834 (27), Nu9056 (28) and various H3-CoA inhibitors (29). We exposed MPM cells to one of these inhibitors, MG 149, and demonstrated that KAT5 inhibition resulted in both significant anti-proliferative effects (Fig. 2B) and the induction of cellular apoptosis (Fig. 3) in cells.

Epigenetic therapies have had mixed results within the clinical setting particularly for agents such as histone deacetylase inhibitors (HDACi) when used as a monotherapy (30). Prior to 2013, estimates suggest that 490 clinical trials had been conducted with HDACi with very limited success (31), and indeed one of the most conspicuous failures for an HDACi was the VANTAGE-014 trial in mesothelioma, which examined the effect of vorinostat in patients with advanced malignant pleural mesothelioma who had progressed on previous chemotherapy (14). Nevertheless, epigenetic therapies remain attractive targets for the treatment of cancer, and recent 'breakthrough therapy FDA designation' for entinostat for breast cancer when added to exemestane in postmenopausal women with $\mathrm{ER}^{+}$metastatic breast cancer whose cancer had progressed after treatment with a non-steroidal aromatase inhibitor (32) and approval of panobinostat for the treatment of multiple myeloma (33) suggest that a better understanding of underlying disease and better stratification of patients may improve clinical outcomes for epigenetic therapies.

MG 149 was shown to induce or upregulate the expression of several pro-inflammatory chemokines/cytokines including CXCL8/IL-8 (Fig. 4). Induction of IL-8 by anti-cancer regimens has been seen before in experimental models of mesothelioma (34). Levels of IL-8 have also been shown to be increased in mesothelioma patients undergoing therapy following pleurectomy or extrapleural pneumonectomy (EPP) (35), or in patients exposed to intrapleural administration of tumor necrosis factor-alpha (TNF- $\alpha$ ) (36). However, elevation of IL-8 levels may not be a reliable marker for response to therapy (37), and the induction of pro-inflammatory cytokines/chemokine's by MG-149 suggests that as a therapy it may elicit cytokine response syndrome (CRS) (38), sometimes observed in MPM (39). Indeed, an additional potential caveat to the utility of MG 149 as a novel therapeutic modality in MPM comes from early research which demonstrated that IL- 8 is pro-angiogenic and acts as an autocrine growth factor in MPM $(40,41)$. Furthermore, inhibition of IL-8 was found to decrease mesothelioma growth both in vitro and in vivo $(42,43)$.

In conclusion, KAT5 may represent a novel therapeutic target for the treatment of MPM. As its expression has been linked to resistance to cisplatin, and current first-line therapy of mesothelioma utilize platin based regimens, future studies should examine whether KAT5 expression is linked to patient outcome, and test the possibility that agents targeting this protein could potentially sensitize (or resensitize) patients to such regimens.

\section{Acknowledgements}

The authors are grateful to Drs Warren Thomas, Yoshitaka Sekido, Dean Fennell and Hannu Norppa for their generosity in providing access to various mesothelioma cell lines. The present study was supported in part by funding for consumables from the Masters in Translational Oncology program (TCD) for Sian Cregan.

\section{References}

1 Wagner JC, Sleggs CA and Marchand P: Diffuse pleural mesothelioma and asbestos exposure in the North Western Cape Province. Br J Ind Med 17: 260-271, 1960.

2. Peto J, Hodgson JT, Matthews FE and Jones JR: Continuing increase in mesothelioma mortality in Britain. Lancet 345: 535-539, 1995.

3. Robinson BW, Musk AW and Lake RA: Malignant mesothelioma. Lancet 366: 397-408, 2005.

4. Driscoll T, Nelson DI, Steenland K, Leigh J, ConchaBarrientos M, Fingerhut $M$ and Prüss-Ustün A: The global burden of disease due to occupational carcinogens. Am J Ind Med 48: 419-431, 2005.

5. Park EK, Takahashi K, Hoshuyama T, Cheng TJ, Delgermaa V, Le GV and Sorahan T: Global magnitude of reported and unreported mesothelioma. Environ Health Perspect 119: 514-518, 2011.

6. Baas P, Fennell D, Kerr KM, Van Schil PE, Haas RL and Peters S; ESMO Guidelines Committee: Malignant pleural mesothelioma: ESMO Clinical Practice Guidelines for diagnosis, treatment and follow-up. Ann Oncol 26 (Suppl 5): v31-v39, 2015.

7. Vogelzang NJ, Rusthoven JJ, Symanowski J, Denham C, Kaukel E, Ruffie P, Gatzemeier U, Boyer M, Emri S, Manegold C, et al: Phase III study of pemetrexed in combination with cisplatin versus cisplatin alone in patients with malignant pleural mesothelioma. J Clin Oncol 21: 2636-2644, 2003.

8. Dawson MA and Kouzarides T: Cancer epigenetics: From mechanism to therapy. Cell 150: 12-27, 2012.

9. Baird A, Richard D, O'Byrne KJ and Gray SG: Epigenetic therapy in lung cancer and mesothelioma. In: Epigenetic Cancer Therapy. 1st edition. Gray SG (ed). Academic Press, pp189-213, 2015.

10. Jenuwein $\mathrm{T}$ and Allis CD: Translating the histone code. Science 293: 1074-1080, 2001.

11. Rothbart SB and Strahl BD: Interpreting the language of histone and DNA modifications. Biochim Biophys Acta 1839: 627-643, 2014.

12. Allis CD, Berger SL, Cote J, Dent S, Jenuwien T, Kouzarides T, Pillus L, Reinberg D, Shi Y, Shiekhattar R, et al: New nomenclature for chromatin-modifying enzymes. Cell 131: 633-636, 2007.

13. Mann BS, Johnson JR, Cohen MH, Justice R and Pazdur R: FDA approval summary: Vorinostat for treatment of advanced primary cutaneous T-cell lymphoma. Oncologist 12: 1247-1252, 2007. 
14. Krug LM, Kindler HL, Calvert H, Manegold C, Tsao AS Fennell D, Öhman R, Plummer R, Eberhardt WE, Fukuoka K, et al: Vorinostat in patients with advanced malignant pleural mesothelioma who have progressed on previous chemotherapy (VANTAGE-014): A phase 3, double-blind, randomised, placebo-controlled trial. Lancet Oncol 16: 447-456, 2015.

15. Farria A, Li W and Dent SY: KATs in cancer: Functions and therapies. Oncogene 34: 4901-4913, 2015.

16. Furdas SD, Kannan S, Sippl W and Jung M: Small molecule inhibitors of histone acetyltransferases as epigenetic tools and drug candidates. Arch Pharm (Weinheim) 345: 7-21, 2012.

17. Yang XJ: The diverse superfamily of lysine acetyltransferases and their roles in leukemia and other diseases. Nucleic Acids Res 32: 959-976, 2004

18. Sapountzi V and Côté J: MYST-family histone acetyltransferases: Beyond chromatin. Cell Mol Life Sci 68: 1147-1156, 2011.

19. Doyon Y and Côté J: The highly conserved and multifunctional NuA4 HAT complex. Curr Opin Genet Dev 14: 147-154, 2004.

20. Bird AW, Yu DY, Pray-Grant MG, Qiu Q, Harmon KE, Megee PC, Grant PA, Smith MM and Christman MF: Acetylation of histone $\mathrm{H} 4$ by Esa1 is required for DNA double-strand break repair. Nature 419: 411-415, 2002.

21. Van Den Broeck A, Nissou D, Brambilla E, Eymin B and Gazzeri S: Activation of a Tip60/E2F1/ERCC1 network in human lung adenocarcinoma cells exposed to cisplatin. Carcinogenesis 33: 320-325, 2012

22. Miyamoto N, Izumi H, Noguchi T, Nakajima Y, Ohmiya Y, Shiota M, Kidani A, Tawara A and Kohno K: Tip60 is regulated by circadian transcription factor clock and is involved in cisplatin resistance. J Biol Chem 283: 18218-18226, 2008.

23. Ghizzoni M, Wu J, Gao T, Haisma HJ, Dekker FJ and George Zheng Y: 6-alkylsalicylates are selective Tip60 inhibitors and target the acetyl-CoA binding site. Eur J Med Chem 47: 337-344, 2012.

24. Baird AM, Gray SG and O'Byrne KJ: Epigenetics underpinning the regulation of the CXC $\left(\mathrm{ELR}^{+}\right)$chemokines in non-small cell lung cancer. PLoS One 6: e14593, 2011.

25. Dragon J, Thompson J, MacPherson M and Shukla A: Differential susceptibility of human pleural and peritoneal mesothelial cells to asbestos exposure. J Cell Biochem 116: 1540-1552, 2015.

26. Tan E, Warren N, Darnton AJ and Hodgson JT: Projection of mesothelioma mortality in Britain using Bayesian methods. Br J Cancer 103: 430-436, 2010.

27. Gao C, Bourke E, Scobie M, Famme MA, Koolmeister T, Helleday T, Eriksson LA, Lowndes NF and Brown JA: Rational design and validation of a Tip60 histone acetyltransferase inhibitor. Sci Rep 4: 5372, 2014.

28. Coffey K, Blackburn TJ, Cook S, Golding BT, Griffin RJ, Hardcastle IR, Hewitt L, Huberman K, McNeill HV, Newell DR, et al: Characterisation of a Tip60 specific inhibitor, NU9056, in prostate cancer. PLoS One 7: e45539, 2012.

29. Yang C, Ngo L and Zheng YG: Rational design of substratebased multivalent inhibitors of the histone acetyltransferase Tip60. ChemMedChem 9: 537-541, 2014.

30. West AC and Johnstone RW: New and emerging HDAC inhibitors for cancer treatment. J Clin Invest 124: 30-39, 2014.
31. Gryder BE, Sodji QH and Oyelere AK: Targeted cancer therapy: Giving histone deacetylase inhibitors all they need to succeed. Future Med Chem 4: 505-524, 2012.

32. Yardley DA, Ismail-Khan RR, Melichar B, Lichinitser M, Munster PN, Klein PM, Cruickshank S, Miller KD, Lee MJ and Trepel JB: Randomized phase II, double-blind, placebocontrolled study of exemestane with or without entinostat in postmenopausal women with locally recurrent or metastatic estrogen receptor-positive breast cancer progressing on treatment with a nonsteroidal aromatase inhibitor. J Clin Oncol 31: 2128-2135, 2013

33. Fenichel MP: FDA approves new agent for multiple myeloma. J Natl Cancer Inst 107: djv165, 2015.

34. Lansley SM, Varano Della Vergiliana JF, Cleaver AL, Ren SH, Segal A, Xu MY and Lee YC: A commercially available preparation of Staphylococcus aureus bio-products potently inhibits tumour growth in a murine model of mesothelioma. Respirology 19: 1025-1033, 2014

35. Yom SS, Busch TM, Friedberg JS, Wileyto EP, Smith D, Glatstein E and Hahn SM: Elevated serum cytokine levels in mesothelioma patients who have undergone pleurectomy or extrapleural pneumonectomy and adjuvant intraoperative photodynamic therapy. Photochem Photobiol 78: 75-81, 2003.

36. Stam TC, Swaak AJ, Kruit WH, Stoter G and Eggermont AM: Intrapleural administration of tumour necrosis factor-alpha (TNFalpha) in patients with mesothelioma: Cytokine patterns and acute-phase protein response. Eur J Clin Invest 30: 336-343, 2000.

37. Nowak AK, Millward MJ, Creaney J, Francis RJ, Dick IM, Hasani A, van der Schaaf A, Segal A, Musk AW and Byrne MJ: A phase II study of intermittent sunitinib malate as second-line therapy in progressive malignant pleural mesothelioma. J Thorac Oncol 7: 1449-1456, 2012

38. Lee DW, Gardner R, Porter DL, Louis CU, Ahmed N, Jensen M, Grupp SA and Mackall CL: Current concepts in the diagnosis and management of cytokine release syndrome. Blood 124: 188-195, 2014.

39. Nowak AK, Cook AM, McDonnell AM, Millward MJ, Creaney J Francis RJ, Hasani A, Segal A, Musk AW, Turlach BA, et al: A phase $1 \mathrm{~b}$ clinical trial of the CD40-activating antibody CP-870,893 in combination with cisplatin and pemetrexed in malignant pleural mesothelioma. Ann Oncol 26: 2483-2490, 2015.

40. Antony VB, Hott JW, Godbey SW and Holm K: Angiogenesis in mesotheliomas. Role of mesothelial cell derived IL-8. Chest 109 (Suppl): 21S-22S, 1996.

41. Galffy G, Mohammed KA, Dowling PA, Nasreen N, Ward MJ and Antony VB: Interleukin 8: An autocrine growth factor for malignant mesothelioma. Cancer Res 59: 367-371, 1999.

42. Cioce M, Canino C, Pulito C, Muti P, Strano S and Blandino G: Butein impairs the protumorigenic activity of malignant pleural mesothelioma cells. Cell Cycle 11: 132-140, 2012.

43. Galffy G, Mohammed KA, Nasreen N, Ward MJ and Antony VB: Inhibition of interleukin-8 reduces human malignant pleural mesothelioma propagation in nude mouse model. Oncol Res 11: 187-194, 1999. 